\title{
7 EFFECTS OF CULTURAL ORIENTATION ON ATTITUDE TOWARD ANONYMITY IN E-COLLABORATION
}

\author{
Yingqin Zhong \\ $\mathrm{Na}$ Liu \\ John Lim \\ Department of Information Systems \\ National University of Singapore \\ Singapore
}

\begin{abstract}
The important role of attitude in the acceptance and diffusion of technology has been widely acknowledged. Greater research efforts have been called for examining the relationships between cultural variables and attitude toward technology. In this regard, this study investigates the impact of cultural orientation (focusing on an individual's degree of collectivism) on attitude toward e-collaboration technology. A theoretical model is proposed and subsequently tested using a questionnaire survey involving 236 data points. Self-reliance, competitive success, and group work orientation are found as significant indicators reflecting an individual's degree of collectivism, which in turn influences willingness to participate, evaluation of collaborative effort, and preference for anonymity feature. Subsequently, the three variables are found to affect perceptions about decision quality, enjoyment, uncertainty, and pressure in e-collaboration.
\end{abstract}

Keywords Attitude, cultural orientation, degree of collectivism, anonymity, e-collaboration

\section{INTRODUCTION}

In the current business environment, the massive shift toward a global digital economy has manifested the prominence of e-collaboration technology in supporting

Please use the following format when citing this chapter:

Zhong, Y., Liu, N., and Lim, J., 2008, in IFIP International Federation for Information Processing, Volume 287, Open IT-Based Innovation: Moving Towards Cooperative IT Transfer and Knowledge Diffusion, eds. León, G., Bernardos, A., Casar, J., Kautz, K., and DeGross, J. (Boston: Springer), pp. 121-138. 
distributed virtual teams. Computer-mediated communications (CMC) tools can increase participation, create greater equality of influence, and reduce domination, production blocking, and cognitive interference. Carrying out group brainstorming tasks in computer-mediated environments has been considered more productive than face-to-face settings in academic institutions, training establishments, governments, and international organizations (Riegelsberger et al. 2005). In decision-making tasks, CMC tools facilitate users in analyzing alternatives, negotiating, and building consensus among group members. These tools are found effective in reducing production blocking, free riding, sucker effect, and evaluation apprehension. They are also found to be positively related to group cohesion and member satisfaction (Reinig and Shin 2002). Many studies have been conducted to investigate the adoption and diffusion of global e-collaboration (e.g., Lefebvre et al. 2006; Munkvold 2005). While many of these studies have pointed out the importance of organizational factors (such as top management support and firm characteristics) in the adoption and diffusion of e-collaboration systems, few have looked at this issue from the individual user's perspective (Lefebvre et al. 2006).

Diffusion is "the process by which an innovation is communicated through certain channels over time among the members of a social system" (Rogers 1995, p. 5). IT diffusion refers to the spread of information technology (Eder and Igbaria 2001). Concerning individual users' progression in forming the attitude toward technology, Rogers' (1995) work highlights the important role that attitude plays in predicting technology acceptance; this has been widely accepted (Albirini 2006). Attitude is defined as "a psychological tendency that is expressed by evaluating a particular entity with some degree of favor or disfavor" (Eagly and Chaiken 1993, p. 1). In other words, attitude reflects some sense of "goodness" or "badness" toward a particular entity perceived by an individual. This paper studies the impact of attitude toward e-collaboration as well as attitude toward collaboration outcomes, with an aim to contribute to the understanding in acceptance and diffusion issues of e-collaboration.

However, the perceived advantage of collaborative technology and the subsequent attitude toward e-collaboration can vary significantly among individual adopters of different cultural backgrounds. Culture plays an imperative role in explaining the differences of patterns exhibited in IT usage (Srite and Karahanna 2006). Prior research has indeed emphasized the influences of culture on technology acceptance and diffusion, as some technology features do embed certain cultural assumptions in their design (Zhang et al. 2007). One of these features is anonymity, which has been commonly used in communication. Promoting equality, openness, and directness in communication, unidentified communications enabled by anonymity features may favor individualists at the expense of collectivist users. Diffusion research has noted that an individual's acceptance of technology is culturally constructed, suggesting the importance of understanding cultural influences in the diffusion of collaborative technology (Anderson 1991). Arising from the trend of globalization, the design of collaborative systems should not only consider technology features but also the intellectual models of users who are implicitly carriers of specific cultural orientations (Zhang et al. 2007).

Culture is fundamentally conceptualized as shared symbols, norms, and values of behaviors in a social collectivity, such as country (Hofstede 1991; Hui and Triandis 1986; Triandis 1995). In particular, cultural orientation reflects an individual's basic beliefs, preferences, or tendencies (Alavi and McCormick 2004); it has a direct impact on technology usage and social behaviors in computer-mediated collaborations (Ji et al. 2004). 
Cultural orientation affects self-concept, verbal and nonverbal expressions, and interpersonal relationships in communications. The interference of CMC tools on communication process connotes the cultural influences; in other words, an individual's cultural orientation contributes to the way in which one accepts and approaches collaborative technologies. For example, studies based on the technology acceptance model (TAM) have reported varying results in terms of predictive power across different cultural contexts including North American, European, Arabic, and Asian countries ( $\mathrm{Hu}$ et al. 1999; Rose and Straub 1998; Straub et al. 1997). In accordance, greater research efforts are needed in investigating the relationships between cultural variables and IT adoption determinants (Leidner and Kayworth 2006; Srite and Karahanna 2006).

A problem in prior IS research is that theoretical propositions proposed about specific national cultures do not address the underlying mechanisms that make these cultures different (Zhang et al. 2007). In this regard, Earley (1993) and Wagner (1995) suggest that the concept of degree of collectivism may explain the difference in individual behaviors. The individualism-collectivism dimension has been described as the single major cultural dimension in social behaviors, and recognized to have a direct impact on how people use technologies (Niles 1998). This dimension, capturing the relative importance people accord to personal interests and to shared pursuits, has been studied at both individual and national levels. Particularly, it has been widely accepted as an index to use in explaining individual differences even within a single country (Alavi and McCornick 2004; Wagner 1995; Workman 2001). Previous research suggests that the degree of collectivism can affect people's intention to participate in unidentified communications, with greater degree of collectivism stimulating more active participation (Watson et al. 1993). For example, in identified communications, individualists tend to contribute more arguments to the discussion in attempting to make their mark on the final decision. In contrast, collectivists would mask their positions to avoid conflicts or delay the process of consensus building, even if they think their arguments are valid. This study will contribute to this line of research by exploring the impact of people's cultural orientation - in terms of degree of collectivism - on their attitude toward e-collaboration, which is an important indicator pertaining to technology acceptance and diffusion.

The remainder of this paper is organized as follows. Section 2 proposes a research model and provides theoretical supports for the hypotheses development. We test this model empirically through a survey study, which is described in section 3 . Next, the data analysis is presented. Finally, findings are discussed and implications are drawn.

\section{RESEARCH MODEL AND HYPOTHESES DEVELOPMENT}

The theory of reasoned action (TRA) (Ajzen and Fishbein 1980) has long been recognized as an imperative framework in attitude studies as well as IT adoption research. TRA suggests that, in order to predict a specific behavior, it is necessary not only to measure general attitude about performing the behavior, but also the attitude concerning the expected results by performing the behavior (Lutz 1981). Building upon TRA to provide a further investigation of attitude toward behavior, Eagly and Chaiken (1993) propose the composite attitude-behavior model, which highlights that attitude 
concerning the expected results — attitude toward target — is affected by attitude toward performing the behavior. Triandis (1995) suggests that an individual's attitude toward performing certain behaviors is heavily influenced by his/her degree of collectivism; these behaviors are embedded in a person's orientation so that he/she generally acts in the same way. Therefore, it is posited that degree of collectivism affects attitude toward performing the behavior, which in turn affects attitude concerning the expected results.

Based on Triandis' work and Eagly and Chaiken's composite attitude-behavior model, we propose a research model as depicted in Figure 1. The related constructs are defined in Table 1. In this model, users' attitude toward e-collaboration is reflected in three constructs including willingness to participate, evaluation of collaborative effort, and preference for anonymity feature. Users' attitude concerning collaboration outcomes is in the form of decision quality, uncertainty, enjoyment, and pressure.

Earley (1993) and Wagner (1995) propose that an individual's collective orientation may be multidimensional and more complex than a simple preference. The cultural dimension individualism-collectivism has been defined as cultural syndromes (Triandis 1995). That is, individualism and collectivism are differentiated by several defining attributes. In line with Anakwe et al. (1999) and Wagner, we investigate degree of collectivism (DC) in terms of four facets including self-reliance, competitive success, group work orientation, and group-goal summation.

\subsection{Degree of Collectivism}

Individualism and collectivism have been widely used at the individual level to conceptualize individual's collective orientations (Alavi and McCornick 2004; Wagner 1995; Workman 2001). In general, when working in groups, individualists prevail in group tasks over relationships and group members are expected to be frank and candid (Wagner 1995). On the other hand, collectivists tend to prioritize group interests over individual recognition and rewards; the focus is on group harmony rather than on confrontation. Collectivists consider relationships are more important than the task. A spec-

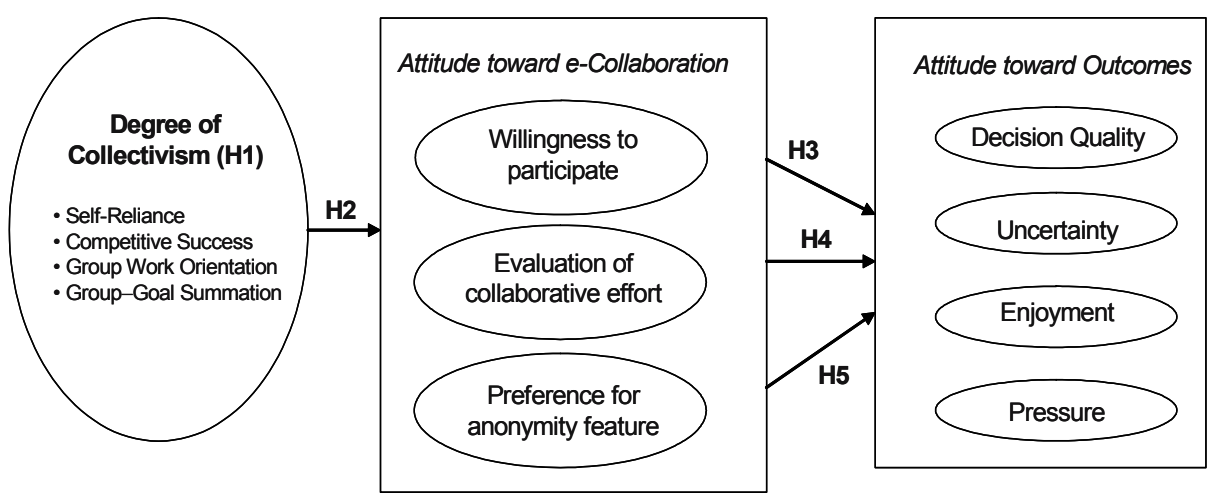

Figure 1. Research Model 
Table 1. Defining the Variables in the Research Model

\begin{tabular}{|l|l|}
\hline \multicolumn{1}{|c|}{ Variable } & \multicolumn{1}{|c|}{ Definition } \\
\hline $\begin{array}{l}\text { Degree of collectivism } \\
\text { (Anakwe et al. 1999; } \\
\text { Wagner 1995) }\end{array}$ & $\begin{array}{l}\text { The degree of an individual's cultural orientation reflecting the } \\
\text { collectivist's characteristics. A spectrum can be formed with } \\
\text { individualism and collectivism as the two ends. }\end{array}$ \\
\hline $\begin{array}{l}\text { Self-reliance (Alavi and } \\
\text { McCormick 2004) }\end{array}$ & Defining self as an autonomous entity independent of groups. \\
\hline $\begin{array}{l}\text { Competitive success } \\
\text { (Triandis 1995) }\end{array}$ & $\begin{array}{l}\text { The tendency to define status and success as a function of } \\
\text { specific accomplishments in competition. }\end{array}$ \\
\hline $\begin{array}{l}\text { Group work orientation } \\
\text { Kim et al. 1994) }\end{array}$ & $\begin{array}{l}\text { The tendency to be driven by social norms, duties, and } \\
\text { obligations. }\end{array}$ \\
\hline $\begin{array}{l}\text { Group-goal summation } \\
\text { (Triandis 1995) }\end{array}$ & The tendency to subordinate personal goals to group goals. \\
\hline $\begin{array}{l}\text { Willingness to participate } \\
\text { (Wagner 1995) }\end{array}$ & $\begin{array}{l}\text { The willingness to contribute to the accomplishment of group } \\
\text { goals in collaborative processes. }\end{array}$ \\
\hline $\begin{array}{l}\text { Evaluation of collaborative } \\
\text { efforts (Spence 1985) }\end{array}$ & $\begin{array}{l}\text { Perception of the potential difficulties involved in the } \\
\text { collaboration process. }\end{array}$ \\
\hline $\begin{array}{l}\text { Preference for anonymity } \\
\text { feature (Klein and Dologite } \\
\text { 2000) }\end{array}$ & $\begin{array}{l}\text { Preferred degree of anonymity supported in the communi- } \\
\text { cation. }\end{array}$ \\
\hline $\begin{array}{l}\text { Decision quality (Ocker and } \\
\text { Yaverbaum 2001) }\end{array}$ & The efficacy in making effective decisions. \\
\hline $\begin{array}{l}\text { Uncertainty (Downey and } \\
\text { Slocum 1975) }\end{array}$ & $\begin{array}{l}\text { The probability of failure in the task due to the lack of } \\
\text { information about behaviors of other members. }\end{array}$ \\
\hline $\begin{array}{l}\text { Enjoyment (Ryan and Deci } \\
\text { 2000) }\end{array}$ & Joy expected to gain from the collaboration. \\
\hline $\begin{array}{l}\text { Pressure (Ryan and Deci } \\
\text { 2000) }\end{array}$ & Anticipating pressure faced in the collaboration. \\
\hline
\end{tabular}

trum can be formed with individualism and collectivism as the two ends, and along this spectrum, points are representing different degree of collectivism (Triandis and Gelfand 1998; Wagner 1995).

First, among individualists, the self is defined to be independent of other members in a group task-self-reliance; the self-reliance factor has been the key idea of many studies investigating degree of collectivism as an individual characteristic (Alavi and McCornick 2004). A second defining attribute of the individualist, competitive success, refers to the emphasis on high self-esteem in the form of winning a competition (Triandis 1995). Third, collectivists tend to be more group oriented, which implies an emphasis on relationship even when they are disadvantaged (Kim et al. 1994). Finally, collectivists are concerned more with the group goals than their personal pursuits. They place top priority in doing what is "right" for the group. On the other hand, when conflict exists, individualists will attempt to reach personal goals prior to the group interests (Triandis 1995). Aligning with existing literature, we expect that

H1a. Self-reliance is negatively related to degree of collectivism.

$H 1 b . \quad$ Competitive success is negatively related to degree of collectivism. 
H1c. Group orientation is positively related to degree of collectivism.

H1d. Group-goal summation is positively related to degree of collectivism.

\subsection{Attitude toward Participating in E-Collaboration}

Group members' voluntarily contribution is essential in group tasks (Wagner 1995). For individualists whose self-definitions arouse interest in the pursuit of personal gains, collaboration is proved attractive only if working with others leads to the attainment of personal benefits that cannot be obtained by working alone. In other instances, individualists are likely to avoid collaboration even when they are working in a group task. In contrast, cooperation is valued by collectivists whose self-definitions favor the pursuit of group interests (Triandis 1995). Research suggests that differences in people's degree of collectivism are likely to affect their collaboration in groups, with greater collectivism stimulating greater willingness and tendency to participate in group work (Zhang et al. 2007).

H2a. Degree of collectivism is positively related to user's willingness to participate.

Moreover, given the same task, individualists tend to perceive more efforts are required in collaboration as compared to collectivists. In attending to group performance and well-being, collectivists are likely to seek and contribute to cooperative endeavors that benefit their groups, irrespective of the immediate personal implications of these endeavors (Spence 1985; Wagner 1995).

H2b. Degree of collectivism is negatively related to user's evaluation of collaboration efforts toward a given task.

Previous studies have reported contradictory effects with the introduction of anonymity in a group process. On one hand, anonymity decreases conformance pressure on the participants in a group setting (Nunamaker et al. 1991; Valacich et al. 1992). On the other hand, studies have suggested that the absence of gender and other status cues eliminates biased devaluation of contributors (Klein and Dologite 2000; Flannagin et al. 2002). In such instances, it is possible for some individualists to reason that they will not receive credit for their notable contributions. Collectivists' self-esteem is not derived from calling attention to their own abilities or contributions; instead, their prime interest is to promote group interests (Wink 1997). Thus, they tend to perceive unidentified communication as an effective mechanism to avoid confrontation and maintain harmony. In contrast, individualists tend to expect that their contributions could arouse attention and gain personal influence in the group decision (Goncale and Staw 2006). Consequently, they tend to prefer identified communication media.

H2c. Degree of collectivism is positively related to user's preference for anonymous features for a given task. 


\subsection{Attitude toward Collaboration Outcomes}

Decision quality (George et al. 1990) is measured as a component of collaboration outcome. Decision quality perceived by the participants is an important indicator to reflect collaboration effectiveness and their efficacy in group potency (Ocker and Yaverbaum 2001). Additionally, past research has found that group task performance in terms of uncertainty should improve when task requirements are matched to a fitting technology (Alavi et al. 1995). Uncertainty is regarded as the lack of information needed to make a decision about a future event (Downey and Slocum 1975), and the probability of loss (Peter and Ryan 1976; Taylor 1974). People participating in an e-collaboration task would perceive uncertainty as the probability of failure in group tasks due to the lack of information about the behaviors of other members. Studies have shown that perceived uncertainty may deter people from participating and actively contributing in a group task (Ryan and Deci 2000).

Intrinsic motivation refers to the incentive about the inherent satisfaction from an activity rather than the actual reward or outcomes (Ryan and Deci 2000). When being intrinsically motivated, a person tends to act for the fun or challenge entailed rather than the external rewards (Ryan and Deci 2000). Intrinsic motivation in the context of ecollaboration refers to positive factors in the form of enjoyment (Kim et al. 2006). Moreover, Ryan and Deci (2000) regard pressure perceived by participants as an important inhibitor for participation in the virtual environment.

To enable effective collaboration, group members must first be willing to share information and then have an opportunity to contribute (Zhang et al. 2007). Depending on how they view themselves relative to other group members, people with high willingness to participate in a group work tend to have more self-initiated efforts contributing to the completion of group tasks even under adverse condition (Augustinova et al. 2005). Hence, willingness to participate is negatively related to uncertainty perceived by users. Also, self-enhancement is a basic need of people to see themselves in a positive light in relation to others; therefore, people with higher willingness to participate tend to have higher intrinsic motivation in joining the e-collaboration tasks and they would perceive the collaboration with more enjoyment and less pressure (Pratt 1998).
H3a. User's willingness to participate is positively related to perceived decision quality.
H3b. User's willingness to participate is negatively related to perceived uncertainty in communication.
H3c. User's willingness to participate is positively related to enjoyment in communication.
H3d. User's willingness to participate is negatively related to pressure in communication.

Tasks requiring a high level of collaboration among members tend to involve conflicts among group members. Research has shown that in an e-collaboration context, members experience fewer hassles and perform better for tasks requiring loose interdependency among members as compared to tasks requiring tight interdependency (Lam 1997). Therefore, people who perceive a task as requiring great collaboration efforts tend to expect a higher level of uncertainty, and consequently worse performance. Similarly, 
they expect less enjoyment and more pressure in tasks demanding greater efforts to resolve conflicts in collaboration.

H4a. User's evaluation of collaboration efforts is negatively related to perceived decision quality.

$H 4 b$. User's evaluation of collaboration efforts is positively related to perceived task uncertainty in communication.

H4c. User's evaluation of collaboration efforts is negatively related to perceived enjoyment in communication.

H4d. User's evaluation of collaboration efforts is positively related to perceived pressure in communication.

Anonymity in e-collaboration may decrease evaluation apprehension (the fear of negative evaluation from other members), increase member participation (Alavi et al. 1995, Chester and Gwynne 1998), and enhance the amount of information generated by the team (Alavi 1994). Higher level of anonymity in collaboration tends to be associated with better decision quality and less uncertainty perceived by members. Moreover, anonymity provides members with equal opportunities to express their ideas by reducing the cues of social status among members. Research has shown that the reduction of social cues in CMC can lead to less fear of disapproval from others, and subsequently encourage greater participation (Dubrovsky et al. 1991; Siegel et al. 1986).

H5a. User's preference for anonymity feature is positively related to perceived decision quality.

H5b. User's preference for anonymity feature is negatively related to perceived uncertainty in communication.

H5c. User's preference for anonymity feature is positively related to perceived enjoyment in communication.

H5d. User's preference for anonymity feature is negatively related to perceived pressure in communication.

\section{RESEARCH METHOD}

A questionnaire survey was conducted for this study. Data were collected from undergraduate students of a large university and module credit was given as incentive. We chose usage of the university collaborative learning system as the target behavior to ensure familiarity and well-formed beliefs from the respondents. Only responses from those who had prior experience in both identified and unidentified communications were included in the analysis, which yielded 236 data points. These respondents came from different countries to ensure sufficient variance in the degree of collectivism; 67 percent of the respondents were male; the age of respondents ranged from 19 to 31, with a mean of 23 (S.D. = 1.845). All research variables were measured using multi-item scales, which were derived from previously published studies (see Table 2). 
Table 2. Measurement Model

\begin{tabular}{|c|c|c|c|c|}
\hline Constructs & $\begin{array}{c}\text { Item } \\
\text { Loading }\end{array}$ & $\begin{array}{l}\text { Composite } \\
\text { Reliability }\end{array}$ & $\begin{array}{c}\text { Cronbach's } \\
\text { Alpha }\end{array}$ & $\begin{array}{l}\text { Variance } \\
\text { Extracted }\end{array}$ \\
\hline $\begin{array}{l}\text { Social Reliance (SR) } \\
\text { (Anakwe et al. 1990; Wagner 1995) } \\
\text { SR1 } \\
\text { SR2 }\end{array}$ & $\begin{array}{l}.804 \\
.810\end{array}$ & .906 & .794 & .829 \\
\hline $\begin{array}{l}\text { Competitive Success (CS) } \\
\text { (Anakwe et al. 1990; Wagner 1995) } \\
\text { CS1 } \\
\text { CS2 } \\
\text { CS3 }\end{array}$ & $\begin{array}{l}.487 \\
.640 \\
.774\end{array}$ & .804 & .630 & .584 \\
\hline $\begin{array}{l}\text { Group Work Orientation (GWO) } \\
\text { (Anakwe et al. 1990; Wagner 1995) } \\
\text { GWO1 } \\
\text { GWO2 } \\
\text { GWO3 } \\
\text { GWO4 }\end{array}$ & $\begin{array}{l}.628 \\
.692 \\
.638 \\
.593\end{array}$ & .864 & .858 & .622 \\
\hline $\begin{array}{l}\text { Group-Goal Summation (GGS) } \\
\text { (Anakwe et al. 1990; Wagner 1995) } \\
\text { GGS1 } \\
\text { GGS2 } \\
\text { GGS3 } \\
\text { GGS4 } \\
\text { GGS5 } \\
\end{array}$ & $\begin{array}{l}.637 \\
.773 \\
.752 \\
.712 \\
.626 \\
\end{array}$ & .831 & .843 & .516 \\
\hline $\begin{array}{l}\text { Willingness to Participate (WP) } \\
\text { (Kim and Song 2004) } \\
\text { WP1 } \\
\text { WP2 } \\
\text { WP3 }\end{array}$ & $\begin{array}{l}.668 \\
.686 \\
.750\end{array}$ & .870 & .776 & .691 \\
\hline $\begin{array}{l}\text { Evaluation of Collaboration Effort } \\
\text { (ECE) (Lu and Argle 1991) } \\
\text { ECE1 } \\
\text { ECE2 }\end{array}$ & $\begin{array}{l}.736 \\
.628\end{array}$ & .940 & .870 & .886 \\
\hline $\begin{array}{l}\text { Preference for Anonymity Feature } \\
\text { (AF) (Kim and Song 2004) } \\
\text { AF1 } \\
\text { AF2 } \\
\text { AF3 } \\
\text { AF4 } \\
\text { AF5 } \\
\text { AF6 }\end{array}$ & $\begin{array}{l}.686 \\
.714 \\
.826 \\
.840 \\
.783 \\
.894\end{array}$ & .921 & .897 & .660 \\
\hline $\begin{array}{l}\text { Decision Quality (DQ) } \\
\text { (Paul et al. 2005) } \\
\text { DQ1 } \\
\text { DQ2 } \\
\text { DQ3 } \\
\end{array}$ & $\begin{array}{l}.441 \\
.550 \\
.246\end{array}$ & .864 & .765 & .679 \\
\hline
\end{tabular}




\begin{tabular}{|l|c|c|c|c|}
\hline \multicolumn{1}{|c|}{ Constructs } & $\begin{array}{c}\text { Item } \\
\text { Loading }\end{array}$ & $\begin{array}{c}\text { Composite } \\
\text { Reliability }\end{array}$ & $\begin{array}{c}\text { Cronbach's } \\
\text { Alpha }\end{array}$ & $\begin{array}{c}\text { Variance } \\
\text { Extracted }\end{array}$ \\
\hline Uncertainty (UNC) & & .767 & .610 & .457 \\
(Son et al. 2006) & .445 & & & \\
UNC1 & .631 & & & \\
UNC2 & .713 & & & \\
UNC3 & .479 & & & \\
UNC4 & & .896 & .682 & \\
\hline Enjoyment (ENJ) & & & & \\
(Ryan and Deci 2000) & .739 & & & \\
ENJ1 & .857 & & & \\
ENJ2 & .762 & & & \\
ENJ3 & .461 & & & \\
ENJ4 & .828 & & & \\
ENJ5 & .716 & & & \\
ENJ6 & & .610 & .603 & \\
\hline Pressure (PRE) & & & & \\
(Ryan and Deci 2000) & .625 & & & \\
PRE1 & .655 & & & \\
PRE2 & .332 & & & \\
PRE3 & .472 & & & \\
PRE4 & .660 & & & \\
PRE5 & & & & \\
\hline
\end{tabular}

\section{DATA ANALYSES}

Partial least squares (PLS), as a structural equation modeling (SEM) technique, was used to assess both the research model and the psychometric prosperities of the scales. SEM analysis was chosen over regression analysis in order to analyze the direct and indirect paths in a single analysis (Barclay et al. 1995; Gefen et al. 2000). Moreover, PLS has been widely used in information systems research to analyze research models consisting of both formative and reflective constructs (Wasko and Faraj 2005). PLS was chosen over LISREL due to the exploratory nature of the research (Barclay et al. 1995; Gefen et al. 2000).

In this study, we treated degree of collectivism as a formative variable, with selfreliance, competitive success, group work orientation, and group-goal summation as subordinate constructs (Chin 1998; Diamantopoulos and Winklhofer 2001). Other variables were modeled as reflective. For the second-order variable, we created the superordinate second-order construct using factor scores for the first-order constructs (Chin et al. 2003; Wold 1989).

\subsection{Measurement Model}

PLS accessed the measurement scales by examining the convergent validity (Cook and Campbell 1979) and discriminant validity (Campbell and Fiske 1959). In PLS, the convergent validity of measurement scales was determined via three tests: item relia- 
Table 3. Discriminant Validity of Constructs

\begin{tabular}{|l|c|c|c|c|c|c|c|c|c|c|c|}
\hline Construct & SR & CS & GWO & GGS & WP & ECE & AF & DQ & UNC & ENJ & PRE \\
\hline SR & .910 & & & & & & & & & & \\
\hline CS & -.330 & .764 & & & & & & & & & \\
\hline GWO & -.283 & .405 & .788 & & & & & & & & \\
\hline GGS & -.300 & .249 & .550 & .718 & & & & & & & \\
\hline WP & -.269 & .180 & .451 & .422 & .831 & & & & & & \\
\hline ECE & .161 & -.202 & -.457 & -.355 & -.455 & .942 & & & & & \\
\hline AF & -.198 & .222 & .040 & .055 & .003 & -.130 & .812 & & & & \\
\hline DQ & -.101 & .331 & .532 & .320 & .309 & -.339 & .177 & .824 & & & \\
\hline UNC & -.236 & .208 & .316 & .333 & .251 & -.376 & .259 & .194 & .676 & & \\
\hline INT & -.110 & .175 & .446 & .217 & .346 & -.337 & .062 & .335 & .108 & .774 & \\
\hline PRE & -.106 & .277 & .170 & .288 & .144 & -.348 & .442 & .172 & .287 & .352 & .526 \\
\hline
\end{tabular}

bility, the composite reliability of constructs, and the average variance extracted by constructs. The test results are reported in Table 2. Given that most constructs had reliability scores above 0.7 and all items had reliability scores above 0.5 , we deemed the measurement items possessed adequate reliability, although some Cronbach's alphas were reported marginally below 0.7 (Chin 1998). Composite reliabilities of most constructs exceed Nunnally's (1978) criterion of 0.7 except for pressure. The average variances extracted were all about 50 percent except for pressure and uncertainty. These results indicated that the convergent validity of the measurement model was fair.

To ensure the discriminant validity, the squared correlations between constructs should be less than the average variance extracted for a construct. Table 3 reported the results of discriminant validity, which was checked by comparing the diagonal to the non-diagonal elements; all items fulfilled the requirements except for the construct pressure. Because of the lack of strong theoretical reasons to remove the construct, pressure remained in the structural model.

\subsection{Structural Model}

The path coefficients and explained variances for the model using a bootstrapping procedure are shown in Figure 2. Each hypothesis corresponded to a path in the structural model. Hypotheses were tested at the 5 percent significance level. The results reveal that self-reliance $(t=-7.9213, p<0.001)$, competitive success $(t=5.0988, p<$ $0.001)$, and group work orientation $(\mathrm{t}=13.9695, \mathrm{p}<0.001)$ were found to be significant indicators for degree of collectivism, but group-goal summation was not $(t=1.4416, p$ $=0.151)$. Degree of collectivism significantly affected willingness to participate $(\mathrm{t}=$ 6.5921, $\mathrm{p}<0.01)$, evaluation of collaboration effort $(\mathrm{t}=-2.8966, \mathrm{p}<0.01)$, and preference of anonymity feature $(\mathrm{t}=2.0746, \mathrm{p}<0.05)$. Willingness to participate was found to have significant impact on perceived decision quality $(t=3.2128, p<0.01)$ and enjoyment $(\mathrm{t}=2.3111, \mathrm{p}<0.05)$, but not on uncertainty $(\mathrm{t}=1.7555, \mathrm{p}=0.08)$ or pressure $(t=0.1059, p=0.916)$. Evaluation of collaboration effort was proven as a significant predictor for decision quality $(\mathrm{t}=-2.3374, \mathrm{p}<0.05)$, uncertainty $(\mathrm{t}=2.9905, \mathrm{p}<0.01)$, and enjoyment $(t=-2.5768, p<0.05)$, but not for pressure $(t=-0.8947, p=0.372)$. The 


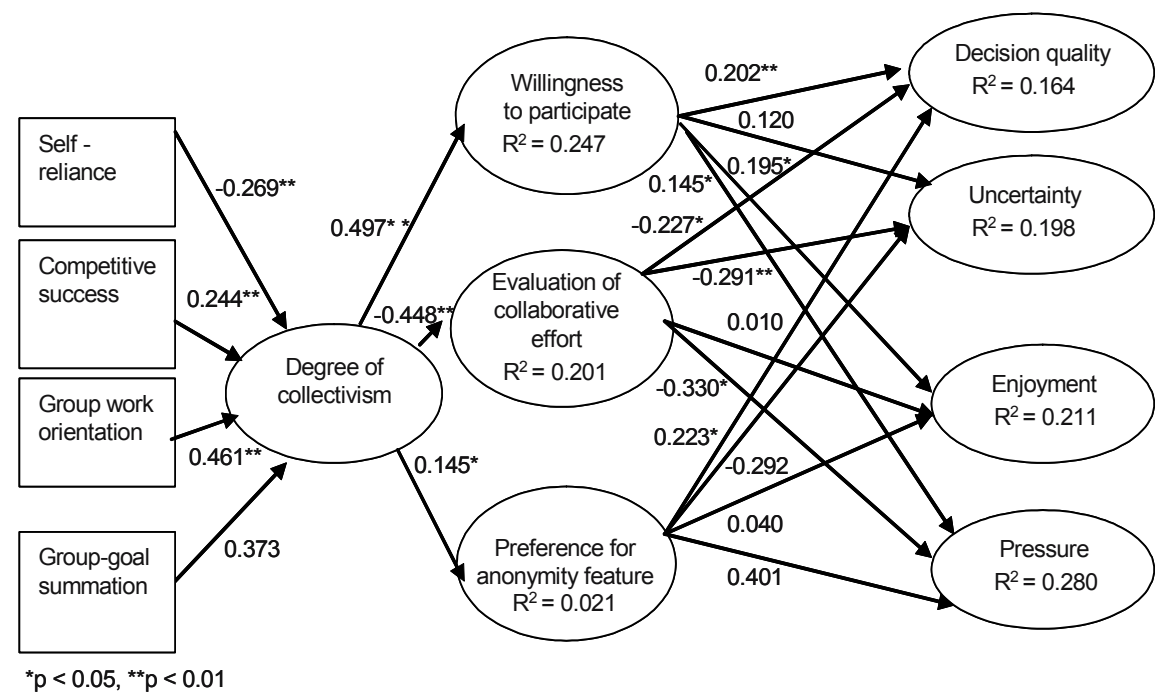

\section{Figure 2. PLS Results}

preference for anonymity feature was revealed to influence perceived decision quality significantly $(\mathrm{t}=2.0994, \mathrm{p}<0.05)$; however, it had no significant impact on uncertainty, enjoyment, or pressure. The results of hypotheses testing were summarized in Table 4.

Table 4. Results of Hypotheses Testing

\begin{tabular}{|l|c|c|c|}
\hline \multicolumn{1}{|c|}{ Hypothesis (Path) } & $\begin{array}{c}\text { Path } \\
\text { Coefficient (b) }\end{array}$ & $\boldsymbol{t}$-Value & $\begin{array}{c}\text { Hypothesis } \\
\text { Supported? }\end{array}$ \\
\hline H1a. SR $\rightarrow$ DC $(+)$ & -0.269 & -7.9213 & Yes \\
\hline H1b. CS $\rightarrow$ DC $(+)$ & 0.244 & 5.0988 & Yes \\
\hline H1.c. GWO $\rightarrow$ DC $(+)$ & 0.461 & 13.9695 & Yes \\
\hline H1d. GGS $\rightarrow$ DC $(+)$ & 0.373 & 1.4416 & No \\
\hline H2a. DC $\rightarrow$ WP $(+)$ & 0.497 & 6.5912 & Yes \\
\hline H2b. DC $\rightarrow$ ECE (-) & 0.488 & -2.8966 & Yes \\
\hline H2c. DC $\rightarrow$ AF $(+)$ & 0.145 & 2.0746 & Yes \\
\hline H3a. WP $\rightarrow$ DQ $(+)$ & 0.202 & 3.2128 & Yes \\
\hline H3b. WP $\rightarrow$ UNC (-) & 0.120 & 1.7555 & No \\
\hline H3c. WP $\rightarrow$ ENJ $(+)$ & 0.195 & 2.3111 & Yes \\
\hline H4a. ECE $\rightarrow$ DQ (+) & -0.227 & -2.3374 & No \\
\hline H4b. ECE $\rightarrow$ UNC $(-)$ & -0.291 & -2.777 & Yes \\
\hline H4c. ECE $\rightarrow$ ENJ $(+)$ & -0.330 & -2.5768 & No \\
\hline H4d. ECE $\rightarrow$ PRE (-) & -0.292 & -0.8947 & No \\
\hline H5a. AF $\rightarrow$ DQ $(+)$ & 0.145 & 2.0994 & Yes \\
\hline H5b. AF $\rightarrow$ UNC (-) & 0.2234 & 2.9905 & No \\
\hline H5c. AF $\rightarrow$ ENJ (+) & 0.040 & 0.3231 & No \\
\hline H5d. AF $\rightarrow$ PRE (-) & 0.401 & 1.0944 & No \\
\hline
\end{tabular}




\section{DISCUSSION AND IMPLICATIONS}

In general, the empirical results are encouraging and provide support for most of the hypotheses. Prior research on individualism-collectivism has found that growing up in a particular country shapes a person's perceptions, which can be used to predict behaviors across a wide variety of situations (Brockner 2003). However, previous research by and large did not explicitly conceptualize and operationalize the multidimensionality of the individualism-collectivism concept in investigating its complex impact on IT acceptance. The current study has further provided a deeper understanding, revealing that self-reliance, competitive success, and group work orientation are significant predictors for degree of collectivism. This study also suggests that group-goal summation is not in line with the other factors in reflecting degree of collectivism. Arguably, it is because there was no group task assigned to the participants in this study; they might not have thought of the possible conflicts between personal goals and group goals. Future studies should look into the influence of this factor in circumstances when personal pursuits and group task do not align.

The results of this study suggest that users' degree of collectivism plays an important role in their attitude toward e-collaboration. Degree of collectivism has been found to be a significant predictor for participants' willingness to participate, evaluation of collaboration effort, and preference of anonymity feature. Participants' willingness to participate is shown to have significant impact on their perceived decision quality and enjoyment gained from the e-collaboration. Participants' evaluation of collaboration effort is proven to be an important predictor for perceived decision quality, uncertainty, and enjoyment. Participants' preference for anonymity feature is shown to have significant impact on their perceived decision quality and uncertainty. Moreover, in this study, the participants do not perceive pressure as an inhibitor which would negatively affect the collaboration; we posit that pressure may be associated with other contextual factors other than perception.

Prior to discussing the implications of our work, some limitations of the study must be acknowledged. Although recent research has found that students essentially have the same values and beliefs as workers, future studies need to examine the findings across a wider range of individuals in different environments and with different collaborative systems (Strite and Karahanna 2006). Different methodologies are also needed to triangulate results and capture actual usage of technology.

Implications can be drawn from the current study for practitioners to design and promote e-collaboration tools. This study advocates that people of varying degree of collectivism perceive e-collaboration differently. As attitude is a dominant factor in predicting acceptance and subsequent usage of a technology, collaborative systems should include functions that facilitate the appropriate level of social support to users with varying degree of collectivism so as to increase their incentive and intention to use the system. For example, users should be allowed to adjust the degree of anonymity in communication to their level of comfort.

In terms of theoretical contributions, the current study adds new insights into the understanding of attitude studies in IT adoption research. More importantly, this study offers detailed characteristics of cultural orientation in predicting user acceptance. To keep our theoretical model succinct and relevant, this study has focused on the cultural 
dimension of individualism-collectivism and the anonymity feature. However, it should be noted that other dimensions of culture may not necessarily follow the same pattern in affecting users' attitude toward e-collaboration, as they can and do display as separate theoretical constructs (El-Shinnawy and Vinze 1997). Accounting for all factors in one study is unwieldy; future research should look into other cultural dimensions and other technological aspects.

\section{CONCLUSIONS}

To understand how attitude toward technology is affected by an individual's cultural orientation, this study investigates the influence of degree of collectivism on evaluations about e-collaboration. Attitude toward e-collaboration is studied in terms of two set of attributes, namely attitude toward participating in e-collaboration and attitude toward outcomes; the links between the two sets of attributes have also been investigated. A theoretical model is proposed and subsequently tested in a questionnaire survey involving 236 data points. Self-reliance, competitive success, and group work orientation are found to be significant indicators concerning a person's degree of collectivism. Degree of collectivism influences willingness to participate, evaluation of collaborative effort, and preference for anonymity feature in e-collaboration. These three variables subsequently affect perceptions about decision quality, enjoyment, uncertainty, and pressure in the collaboration.

\section{References}

Ajzen, I., and Fishbein, M. 1980. Understanding Attitudes and Predicting Social Behavior, Englewood Cliffs, NJ: Prentice-Hall.

Alavi, M. 1994. "Computer-Mediated Collaborative Learning: An Empirical Evaluation," MIS Quarterly (18:2), pp. 159-174.

Alavi, M., Wheeler, B. C., and Valacich J. S. 1995. "Using IT to Reengineer Business Education: An Exploratory Investigation of Collaborative Telelearning," MIS Quarterly (19:3), pp. 293-312.

Alavi, S. B., and McCormick, J. 2004 "Theoretical and Measurement Issues for Studies of Collective Orientation in Team Contexts," Small Group Research (35:2), pp. 111-127.

Albirini, A. 2006. "Teachers' Attitudes toward Information and Communication Technologies: The Case of Syrian EFL Teachers," Computers \& Education (47), pp. 373-398.

Anakwe, U. P., Kessler, E. H., and Christensen, E. W. 1999. "Distance Learning and Cultural Diversity: Potential Users' Perspective," The International Journal of Organizational Analysis (7:3), pp. 224-243.

Anderson, J. L. 1991. "The Receptor Culture and the Consultant's Visit," Notes on Translation (5:4), pp. 23-30.

Augustinova, M., Oberlé, D., and Stasser, G. L. 2005. "Differential Access to Information and Anticipated Group Interaction: Impact on Individual Reasoning," Journal of Personality and Social Psychology (88:4), pp. 619-631.

Barclay D. C., Higgins, C., and Thompson, R. 1995. "The Partial Least Squares Approach to Causal Modeling: Personal Computer Adoption and Use as an Illustration," Technology Studies (2:2), pp. 285-308. 
Brockner, J. 2003. "Unpacking Country Effects: On the Need to Operationalize the Psychological Determinants of Cross-National Differences," Research in Organizational Behavior (25), pp. 333-367.

Campbell, D. T., and Fiske, D. W. 1959. "Convergent and Discriminant Validation by the Multitrait-Multimethod Matrix," Psychological Bulletin (56:1), pp. 81-105.

Chester, A., and Gwynne, G. 1998. "Online Teaching: Encouraging Collaboration through Anonymity," Journal of Computer-Mediated Communication (4:2) (http://jcmc.indiana.edu/ vol4/issue2/chester.html; accessed on March 14, 2008).

Chin, W. W. 1998. "Issues and Opinions on Structural Equation Modeling," MIS Quarterly (22:1), pp. 7-16.

Chin, W. W., Marcolin, B. L., and Newsted, P. R. 2003. "A Partial Least Squares Latent Variable Modeling Approach for Measuring Interaction Effects: Results from a Monte Carlo Simulation Study and an Electronic-Mail Emotion/Adoption Study," Information Systems Research (14:2), pp. 189-217.

Cook M., and Campbell, D. T. 1979. Quasi-Experimentation: Design and Analysis Issues for Fields Settings, Boston: Houghton Mifflin.

Diamantopoulos, A., and Winklhofer, H. M. 2001. "Index Construction with Formative Indicators: An Alternative to Scale Development," Journal of Marketing Research (38:2), pp. 269-277.

Downey, H. K., and Slocum, J. W. 1975. "Uncertainty: Measures, Research, and Sources of Variation," Academy of Management Journal (18:3), pp. 562-578.

Dubrovsky, V. J., Kiesler, S., and Sethna, B. N. 1995. "The Equalization Phenomenon: Status Effects in Computer-Mediated and Face-to-Face Decision-Making Groups," Human Computer Interaction (6), pp. 119-146.

Eagly, A. H., and Chaiken, S. 1993. The Psychology of Attitude, Fort Worth, TX: Harcourt Brace Jovanovich Publishers.

Earley, P. C. 1993. "East Meets West Mideast: Further Explorations of Collectivistic and Individualist Work Groups," Academy of Management Journal (36), pp. 319-348.

Eder, L. B., and Igbaria, M. 2001. "Determinants of Intranet Diffusion and Infusion," OmegaThe International Journal of Management Science (29), pp. 233-242.

El-Shinnawy, M., and Viaze, A. 1997. "Technology, Culture and Persuasiveness: A Study of Choice Shifts in Group Settings," International Journal of Human Computer Studies (47), pp. 473-496.

Flanagin, A. J., Tiyaamornwong, V., O’Connor, J., and Seibold, D. R. 2002. "ComputerMediated Group Work: The Interaction of Member Sex and Anonymity," Communication Research (29:1), pp. 66-93.

Gefen, D., Straub, D., and Boudreau, M. C. 2000. "Structural Equation Modeling Techniques and Regression: Guidelines for Research Practices," Communications of the AIS (7:7), pp. 1-78.

George, J. F., Easton, G. K., Nunamaker Jr., J. F., and Northcraft, G. B. 1990. "A Study of Collaborative Group Work with and Without Computer-based Support," Information Systems Research (1:4), pp. 394-415.

Goncale, J. A., and Staw, B. M. 2006. "Individualism-Collectivism and Group Creativity," Organizational Behavior and Human Decision Processes (100), pp. 96-109.

Hofstede, G. 1991. Cultures and Organizations: Software of the Mind, London: McGraw-Hill. Hu, P. J., Chau, P. Y. K., Sheng, O. R. L., and Tam, K. Y. 1999. "Examining the Technology Acceptnace Model Using Physical Acceptance of Telemedicine Technology," Journal of Management Information Systems (16:2), pp. 91-112.

Hui, C. H., and Triandis, H. C. 1986. "Individualism and Collectivism: A Study of CrossCultural Researchers," Journal of Cross-Cultural Psychology (17), pp. 225-248. 
Ji, L. J., Zhang, Z., and Nisbett, R. E. 2004. "Is it Culture or Is it Language? Examination of Language Effects in Cross-Cultural Research on Categorization," Journal of Personality and Social Psychology (87:1), pp. 57-65.

Kim, M. S., Sharkey, W. F., and Singelis, T. M. 1994. "Relationship between Individuals' SelfConstruals and Perceived Importance of Interactive Constraints," International Journal of Intercultural Relationships (18), pp. 117-140.

Kim, Y. H., Hamilton, R., Zheng, J., and Baylor, A. L. 2006. "Scaffolding Learner Motivation through a Virtual Peer," in Proceedings of the $7^{\text {th }}$ International Conference on Learning Sciences, S. A. Barab, K. E. Hay, and D. T. Hickey (eds.), Bloomington, IN, June 27-July 1, pp. 335-341.

Kim, Y. J., and Song, J. 2004. "Unveiling User Characteristics in Virtual Communities and the Impact on E-Commerce," in Proceedings of the $25^{\text {th }}$ International Conference on Information Systems, R. Agarwal, L. Kirsch, and J. I. DeGross (eds.), Washington, DC, December 12-15, pp. 207-220.

Klein, E. E., and Dologite, D. G. 2000. "The Role of Computer Support Tools and Gender Composition in Innovative Information System Idea Generation by Small Groups," Computers in Human Behavior (16), pp. 111-139.

Lam, S. K. 1997. "The Effects of Group Decision Support Systems and Task Structures on Group Communication and Decision Quality," Journal of Management Information Systems (13:4), pp. 193-215.

Lefebvre, L. A., Lefebvre, G., Hen, L., and Mendgen, R. 2006. "Cross-Border E-Collaboration for New Product Development in the Automotive Industry," in Proceedings of the $39^{\text {th }}$ Annual Hawaii International Conference on System Sciences, Los Alamitos, CA: IEEE Computer Society Press, pp. 8-18.

Leidner D. E., and Kayworth, T. 2006. "Review: A Review of Culture in Information Systems Research: Toward a Theory of Information Technology Culture Conflict," MIS Quarterly (30:2), pp. 357-399.

Lu, L., and Argyle, M. 1991. "Happiness and Cooperation," Personality and Individual Differences (12), pp. 1019-1030.

Lutz, R. J. 1981. "The Role of Attitude Theory in Marketing," in Perspectives in Consumer Behavior ( $3^{\text {rd }}$ ed.), H. H. Kassarjian and T. S. Robertson (eds.), Englewood Cliffs, NJ: Prentice Hall, pp. 233-250.

Munkvold, B. E. 2005. "Experiences from Global E-Collaboration: Contextual Influences on Technology Adoption and Use," IEEE Transactions on Professional Communication (48:1), pp. $78-86$.

Niles, F. S. 1998. "Individualism-Collectivism Revisited," Cross-Cultural Research (32), pp. 315-341.

Nunamaker, J. F., Dennis, A. R., Valacich, J. S., Vogel, D. R., and George, J. F. 1991. "Electronic Meeting Systems to Support Group Work," Communications of the ACM (34:7), pp. 41-60.

Nunnally, J. C. 1978. Psychometric Theory (2 $2^{\text {nd }}$ ed.), New York: McGraw-Hill.

Ocker, R. J., and Yaverbaum, G. J. 2001. "Collaborative Learning Environments : Exploring Student Attitudes and Satisfaction in Face-to-face and Asynchronous Computer Conference Settings," Journal of Interactive Learning Research (12:4), pp. 427-448.

Paul, S., Samarah, I. M., Seetharaman, P., and Mykytyn Jr., P. P. 2005. "An Empirical Investigation of Collaborative Conflict Management Style in Group Support System-Based Global Virtual Teams," Journal of Management Information System (21:3), pp. 185-222.

Peter, J. P., and Ryan, M. J. 1976. "Investigation of Perceived Risk at Brand Level," Journal of Marketing Research (13:2), pp. 184-188. 
Pratt, M. C. 1998. "To Be or Not to Be? Central Questions in Organizational Identification," in Identity in Organizations: Building Theory through Conversations, D. A. Whetten and P. C. Godfrey (eds.), Thousand Oaks, CA: Sage Publications, pp. 171-207.

Reinig, B. A., and Shin, B. 2002. "The Dynamic Effects of Group Support Systems on Group Meetings," Journal of Management Information Systems (19:2), pp. 303-325.

Riegelsberger, J., Sasse, M. A., and McCarthy, J. D. 2005. "The Mechanics of Trust: A Framework for Research and Design," International Journal of Human-Computer Studies (62:3), pp. 381-422.

Rindfleisch, A., and Heide, J. B. 1997. "Transaction Cost Analysis: Past, Present, and Future Applications," Journal of Marketing (61:4), pp. 30-54.

Rogers, E. M. 1995. Diffusion of Innovations ( $4^{\text {th }}$ ed.), New York: The Free Press.

Rose, G., and Straub, D. 1998. "Predicting General IT Use: Applying TAM to the Arabic World," Journal of Global Information Management (6:3), pp. 39-46.

Ryan, R. M., and Deci, E. L. 2000. "Intrinsic and Extrinsic Motivations: Classic Definitions and New Directions," Contemporary Educational Psychology (25), pp. 54-67.

Siegel, J., Dubrovsky, V. J., Kiesler, S., and McGuire, T. W. 1986. "Group Processes in Computer-Mediated Communication," Organizational Behavior and Human Decision Processes (3), pp. 157-187.

Son, J. Y., Kim, S. S., and Riggins, F. J. 2006. "Consumer Adoption of Net-Enabled Infomediaries: Theoretical Explanations and an Empirical Test," Journal of the Association for Information System (7:7), pp. 473-508.

Spence, J. T. 1985. "Achievement American Style: The Rewards and Cost of Individualism," American Psychology (40), pp. 1285-1295.

Srite, M., and Karahanna, E. 2006. "The Role of Espoused National Cultural Values in Technology Acceptance," MIS Quarterly (30:3), pp. 679-704.

Straub, D. W., Keil, M., and Brenner, W. 1997. "Testing the Technology Acceptance Model Across Cultures: A Three Country Study," Information and Mangement (33), pp. 1-11.

Taylor, J. W. 1974. "Role of Risk in Consumer Behavior," Journal of Marketing (38:2), pp. 54-60.

Trandis, H. C. 1995. Individualism and Collectivism, Boulder, CO: Westview Press Inc.

Triandis, H. C., and Gelfand, M. J. 1998. "Converging Measurement of Horizontal and Vertical Individualism and Collectivism," Journal of Personality and Social Psychology (74), pp. 118-128.

Valacich, J. S., Jessup, L. M. Dennis A. R., and Nunamaker, J. F. 1992. "A Conceptual Framework for Anonymity in Electronic Meetings," Group Decision and Negotiation (1:3), pp. 219-241.

Wagner III, J. A. 1995. "Studies of Individualism-Collectivism: Effects on Cooperation in Groups," Academy of Management Journal (38), pp. 152-172.

Wasko, M. M., and Faraj, S. 2005. "Why Should I Share? Examining Social Capital and Knowledge Contribution in Electronic Networks or Practice," MIS Quarterly (29:1), pp. 35-57.

Watson, W. E., Kumar, K., and Michelson, L. K. 1993. "Cultural Diversity's Impact on Interaction Process and Performance: Comparing Homogeneous and Diverse Ttask Groups," Academy of Management Journal (36), pp. 590-602.

Wink, P. 1997. "Beyond Ethnic Differences: Contextualizing the Influence of Ethnicity on Individualism and Collectivism," Journal of Social Issues (53), pp. 329-349.

Wold, H. 1989. "Introduction to the Second Generation of Multivarate Analysis," in Theoretical Empiricism H. Wold ed.), New York: Oragon House, pp. 7-11.

Workman, M. 2001. "Collectivism, Individualism and Cohesion in a Team-Based Occupation," Journal of Vocational Behavior (58), pp. 82-97. 
Zhang, D., Lowry, P. B., Zhou, L., and Fu, X. 2007. "The Impact of Individualism-Collectivism, Social Presence, and Group Diversity on Group Decision Making under Majority Influence," Journal of Management Information Systems (23:4), pp. 53-80.

\section{About the Authors}

Yingqin Zhong is currently a doctoral candidate in the Department of Information Systems at the National University of Singapore. She holds a B.Sc. (Honors) degree in Computing and a M.Sc. degree in Information Systems from the National University of Singapore. Her research interests center around the cultural issues in e-collaboration, focusing on the adoption and usage of collaborative learning technology. She has recently coordinated a data collection effort that involves institutions in China. Her papers have been published in Information Resources Management Journal and International Journal of Web-Based Learning and Teaching Technologies. Yingqin can be reached by e-mail at zhongyin@comp.nus.edu.sg.

Liu Na is a Ph.D. candidate in the Department of Information Systems at the School of Computing, National University of Singapore. She received her B.Sc.(Honors) in Information Systems from NUS in 2006. Her research interest focuses on IT and education, particularly from the human-computer interaction perspective. Her work has been presented at the Pacific Asia Conference on Information Systems. Liu can be reached by e-mail at liuna@comp.nus.edu.sg.

John Lim is an associate professor in the School of Computing at the National University of Singapore. Concurrently, he heads the Information Systems Research Lab. Dr. Lim graduated with First Class Honors in Electrical Engineering and a M.Sc. in MIS from the National University of Singapore, and a Ph.D. from the University of British Columbia. His current research interests include e-commerce, collaborative technology, negotiation support, IT and education, and IS implementation. He has published in MIS and related journals including Journal of Management Information Systems, Journal of Global Information Management, Decision Support Systems, International Journal of Human Computer Studies, Organizational Behavior and Human Decision Processes, Behavior and Information Technology, International Journal of Web-based Learning and Teaching Technologies, Journal of Database Management, and Small Group Research. He can be reached by e-mail at jlim@nus.edu.sg. 